\title{
Editorial: Human-centered design of systems in honor of Professor Gavriel Salvendy
}

\author{
Hans-Jorg Bullinger • Shimon Y. Nof
}

Published online: 22 August 2009

(C) Springer Science+Business Media, LLC 2009

Professor Gavriel Salvendy has had remarkable contributions to the education and research of human-centered design of systems. This Special Issue is organized in honor of his retirement from Purdue University, celebrating his leadership and many significant contributions to industrial engineering, human factors and ergonomics.

In an outstanding academic career spanning 40 years so far, Professor Salvendy has supervised 51 doctoral dissertations, authored over 450 publications, including 30 books and 250 journal articles. He also serves as the founding editor of two scientific journals. Among his many honors, he was awarded in 2007 the John Fritz Medal and in 2008 the John L. Imhoff Global Excellence Award, by the American Society of Engineering Education. Upon Professor Salvendy's retirement from Purdue University and its School of Industrial Engineering, a Symposium was arranged in his honor in August 2008. This Special Issue was inspired by the participants of that Symposium.

Professor Gavriel Salvendy has been a distinguished pillar of Purdue and its School of IE. His accomplishments and leadership have significantly impacted the development of the Human Factors and Industrial Engineering programs at Purdue University and universities worldwide; his books, handbooks, scientific conferences and publications in these areas have significantly impacted our profession, and his many students continue to lead prominent companies and universities. We are excited about sharing this unique Special Issue with you. The nine selected articles are organized

\footnotetext{
H.-J. Bullinger

Fraunhofer Society, Munich, Germany

S. Y. Nof $(\varangle)$

Purdue University, West Lafayette, IN, USA

e-mail: nof@purdue.edu
}

in two main areas: (1) user interface design and usability; and (2) human-centered systems design and applications.

There are four articles in the area of user interface design and usability:

"What is still wrong with the World-Wide Web?: An update after a decade" by Lightner and Zeng, discusses the type of troubles Internet users are experiencing today, compared to those back from the early days of the WWW, by presenting an early survey as basis and a follow-up survey after a decade; then comparing the two surveys.

"Vibration perception and excitatory direction for haptic devices" by Hwang and Hwang, investigates haptic interfaces in which system-feedback is provided via vibration, addresses design factors of the vibration, and examines the excitatory direction as a design factor in terms of sensitivity and emotion.

"The effects of target location and target distinction on visual search in a depth display" by Reis, Liu, Havig, and Heft, discusses advances in 3D visual display technology, and investigates the effects of target location and target distinction on visual search in a depth display, and the interactions between them.

"Query translation-based cross-language print defect diagnosis based on the fuzzy Bayesian model" by Choe, Lehto, and Allebach, presents a study on automated diagnosis of print defects based on automatic processing of natural language, discusses the processing of queries stated in different languages using single language adapted models and automatic translation, employing fuzzy Bayesian prediction. The article then investigates the prediction accuracy of models in different settings.

The next five articles focus on human-centered systems design and applications:

"Improving efficiencies and patient safety in healthcare through human factors and ergonomics" by Duffy, presents 
a review of human factors and ergonomics in healthcare and patient safety, and describes past and present research and teaching activities, with a reappraisal of where research needs to go in the future.

"Human centered design in the air transportation system" by Landry, provides an overview of the current situation and upcoming challenges in air traffic control system from the perspective of human centered design, describes today's problems such as scalability of the system without disruption or loss of safety, and discusses areas for innovations, including advances in computing the safety of complex humanintegrated systems, understanding and measuring situation awareness, and visualizations of complex data.

"A novel agent-based concept of household appliances" by Steblovnik and Zazula, investigates a multi-agent based architecture, derived from belief-desire-intention agents, to enable reconfiguration of agent-based household appliances during the design, production and implementation phases, and presents an agent-based simulator for design and implementation of household appliances.

"Improving computer-mediated information alignment in production organizations" by Palmer and Caldwell, introduces a developing project to describe and quantify concepts of information alignment between computerized information systems and other aspects of information sharing in a production facility, and discusses critical aspects of information alignment.

"Analysis of effectiveness and benefits of collaboration modes with information- and knowledge-sharing" by Yoon, Matsui, Yamada, and Nof, focuses on how collaborative decision makers can share information and knowledge, and presents the potential benefits of information and knowledge sharing, by using an ERP simulation tool to show that total profit and due-date performance are improved by information and knowledge sharing.

These nine articles represent some of the leading topics in human-centered design of systems in production, manufacturing and service. They aim to honor the impact and influence by the pioneering contributions of Professor Salvendy and his many students. The guest editors wish to thank the contributing authors, the referees, the editorial office and Springer colleagues who have all helped us deliver this issue to you in honoring Professor Salvendy. 